\title{
A Photoreactive Polyimide with Main-Chain Chalcone Moiety
}

\author{
Ke Feng, Toshihiko Matsumoto* and Toshikazu Kurosaki
}

Department of Industrial Chemistry, Faculty of Engineering

Tokyo Institute of Polytechnics, 1583 Iiyama, Atsugi, Kanagawa 243-02, Japan

\begin{abstract}
A fully imidized photosensitive polyimide with a chalcone moiety in the main chain was developed. It was derived from 4,4'-diaminochalcone and 6FDA (2,2-bis(3,4-dicarboxyphenyl) hexafluoropropane dianhydride). The polyimide was characterized and its photochemical behavior was investigated in the film state and in the solution using UV and IR spectroscopy. The polyimide exhibited a good thermal stability $\left(5 \%\right.$ weight loss temperature at $\left.485^{\circ} \mathrm{C}\right)$ and a high glass transition temperature of $267^{\circ} \mathrm{C}$ as well as an excellent solubility even in low polar solvents such as 1,4-dioxane and chloroform. This negative working polyimide also possessed a photosensitivity of $130 \mathrm{~mJ} / \mathrm{cm}^{2}$ with a high contrast of 3.4 when exposed to light from a Xenon lamp.
\end{abstract}

Keywords: photoreactive polyimide, photo-crosslinking, photosensitive, chalcone

\section{Introduction}

Photosensitive polyimides are very attractive for semiconductor fabrication since the process of image generation could be greatly simplified by using them. In the common negative working type, the photosensitive polyimides are prepared from soluble poly(amic acid)s, where crosslinking sites are attached to amic acids through ester and acid amine ion linkages.[1,2] Such polyimide precursors usually suffer from excessive volume contraction during thermal curing for imidization. Therefore, a soluble and fully imidized polyimide with photosensitivity is more desirable in lithography.

On the other hand, although the chalcone group has been used in polymeric photoresists for many years, most reports concerned polymers with sidechain chalcone units[3-5] because of the rigid-rod feature of the main-chain-containing chalcone polymers which leads to the difficulties in their solubility. The soluble polymers with the chalcone group in the main chain have been rarely reported.

The work described here involves the synthesis and characterization of a novel soluble photosensitive polyimide, which bears both a chalcone group and trifluoromethyl unit on its polymer backbone. This molecule design is based on several previous studies. (1) By introducing a polyalicyclc unit[6-8] or a bulky trifluoroalkyl substituent[6,9-10] into the polymer main chains, the solubility of polyimides was improved due to the reduced interaction of the polymer-polymer chains. Furthermore, (2) this method was also employed to yield transparent polyimide films thus contributing to their high sensitivity.[9-10] (3) The chalcone group was considered to offer high sensitivity to UV radiation and the chemical resistance in the resultant polymers.[11-12]

Another objective of this work includes the 
investigation of the photochemical behavior for this polyimide in solution and as films.

\section{Experimental}

2.1. Materials and Measurements

$N, N$-Dimethylacetamide (DMAc) used for polycondensation was dried over $\mathrm{CaH}_{2}$ and then fractionally distilled under reduced pressure and stored over $4 \AA$ molecular sieves. 2,2 -Bis $(3,4$ dicarboxyphenyl)hexafluoropropane dianhydride (6FDA) was obtained from American Hoechst. All other reagents and solvents were obtained from commercial sources and used as received.

Infrared spectra were measured using a JASCO VALOR-III Fourier transform spectrometer. UV VIS spectra were recorded using a JASCO Ubest-50 spectrophotometer. ${ }^{1} \mathrm{H}$ and ${ }^{13} \mathrm{C}$ NMR spectra were obtained using a JEOL JNM-EX 400WB spectrometer operating at 400 and $100 \mathrm{MHz}$, respectively. The proton signals of the ${ }^{1} \mathbf{H}$ NMR spectrum were assigned in the $\mathrm{H}, \mathrm{H}$-COSY spectra. Thermal analyses were carried out using a Seiko SSC 5200TG/DTA 220 instrument at a heating rate of $10^{\circ} \mathrm{C} /$ $\mathrm{min}$ in nitrogen for the thermogravimetric analysis (TGA) and using a Seiko SSC 5200-TMA/SS 100 instrument with a constant load of $10 \mathrm{~g}$ (stress $=0.125$ $\mathrm{MPa}$ ) at a heating rate of $10^{\circ} \mathrm{C} / \mathrm{min}$ in air for determination of the glass transition temperature. Elemental analysis was performed at the Shonan Analysis Center Inc.(Yokohama). Inherent viscosity was measured with an Ostwald viscometer in a 0.5 $\mathrm{g} / \mathrm{dL}$ DMAc solution of polyimides at $30^{\circ} \mathrm{C}$. The scanning electron micrograph of the polyimide pattern was taken using a JEOL JSM-5310 Scanning Microscope. The polyimide film thicknesses were determined with a Dektak ${ }^{3}$ ST Surface Profiler (Veeco Sloan Technology Inc.).

\subsection{Preparation of 4,4'-Diaminochalcone (4DAC)}

From the Friedel-Crafts reaction[13] of acetanilide with acetylchloride, 4-acetylacetanilide (4a) was obtained with a yield of $82 \%$ and had a mp of $168{ }^{\circ} \mathrm{C}$. The redox of 4-nitrotoluene in the presence of sodium sulfide and sublimed sulfur gave 4-aminobenzaldehyde (mp 64-66 ${ }^{\circ} \mathrm{C}$, Lit.[14] $\mathrm{mp} 68$ $70^{\circ} \mathrm{C}$ ), followed by acetylation to form 4-acetamidobenzaldehyde (4b): $\mathrm{mp} 155^{\circ} \mathrm{C}$. In an ice bath, $4 \mathrm{~b}$ $(6.70 \mathrm{~g}, 0.041 \mathrm{~mol})$ was dissolved in $80 \mathrm{~mL}$ methanol then added to the mixture of $4 \mathrm{a}(7.28 \mathrm{~g}, 0.041 \mathrm{~mol})$, methanol $(20 \mathrm{~mL})$ and $1 \mathrm{M} \mathrm{NaOH}(50 \mathrm{~mL})$. The solution was stirred for $3 \mathrm{~h}$ at room temperature and cooled in a refrigerator to give 4,4'-diacetamidochalcone (4c) with a yield of $95 \%$ and mp $269^{\circ} \mathrm{C}$. After $4 \mathrm{c}(4.62 \mathrm{~g}, 0.014 \mathrm{~mol})$ in $7 \%$ aq. $\mathrm{HCl}$ acid $(200$ $\mathrm{mL}$ ) was heated with reflux for $3 \mathrm{~h}$, an orange crude product was produced then collected by filtration. A final recrystallization from $\mathrm{H}_{2} \mathrm{O}$ gave $3.05 \mathrm{~g}$ of diamine 4DAC with a yield of 85\%: $\operatorname{mp}$ (DTA) 178 ${ }^{\circ} \mathrm{C}$ and $78^{\circ} \mathrm{C}$ (monohydrate). IR $\left(\mathrm{KBr}, \mathrm{cm}^{-1}\right) \mathrm{NH}_{2}$ at 3436 and $3332, \mathrm{~N}-\mathrm{H}$ at $1628, \mathrm{C}=\mathrm{C}$ and aromatic $\mathrm{C}=\mathrm{C}$ at 1596, 1569 and 1514; UV (methanol) $\lambda_{\text {max }}=397$ $\mathrm{nm}, \varepsilon_{\max }=37200 ;{ }^{1} \mathrm{H}$ NMR (DMSO- $\left.d_{6}, \mathrm{ppm}\right) \delta$ $7.86\left(2 \mathrm{H}, \mathrm{d}, J_{2,3}=8, \mathrm{H}-2\right), 7.50\left(2 \mathrm{H}, \mathrm{d}, J_{2,3^{\prime}}=8, \mathrm{H}-2^{\prime}\right)$, $7.49(2 \mathrm{H}, \mathrm{s}, \mathrm{CH}=\mathrm{CH}), 6.59\left(2 \mathrm{H}, \mathrm{d}, J_{3,2}=8, \mathrm{H}-3\right)$, $6.58\left(2 \mathrm{H}, \mathrm{d}, J_{3^{\prime}, 2^{\prime}}=8, \mathrm{H}-3^{\prime}\right), 6.01\left(2 \mathrm{H}, \mathrm{s}, \mathrm{NH}_{2}\right), 5.73$ $\left(2 \mathrm{H}, \mathrm{s}, \mathrm{NH}_{2}\right) ;{ }^{13} \mathrm{C} \mathrm{NMR}$ (DMSO- $\left.d_{6}, \mathrm{ppm}\right) \delta 185.8$ (C=O), 153.2 (C-4), 151.2 (C-4'), 142.8 (CH, C-1' side), 130.5 (C-2), 130.3 (C-2'), 126.0 (C-1'), 122.4 (C-1), 115.8 (CH, C=O side), $113.5\left(\mathrm{C}^{\prime} 3^{\prime}\right), 112.6(\mathrm{C}-$ 3). Anal. Calcd For $\mathrm{C}_{15} \mathrm{H}_{14} \mathrm{ON}_{2}-\mathrm{H}_{2} \mathrm{O}: \mathrm{C}, 70.29 ; \mathrm{H}$, 6.29; N, 10.93; Found: C, 70.38; H, 6.33; N, 10.82 .

\subsection{Preparation of Polyimide}

In a 30-ml three-necked flask equipped with a magnetic stirrer and a nitrogen inlet were placed 6FDA (0.8885 g, $2.0 \mathrm{mmol})$, DMAc $(6.0 \mathrm{~mL})$ and diamine 4DAC $(0.5127 \mathrm{~g}, 2.0 \mathrm{mmol})$. The mixture was stirred in a nitrogen atmosphere for 2 days at room temperature, then acetic anhydride $(12 \mathrm{mmol})$ and pyridine $(0.3 \mathrm{~mL})$ were added, and held at 70 $80^{\circ} \mathrm{C}$ for $5 \mathrm{~h}$. The resulting solution was poured into $\mathrm{H}_{2} \mathrm{O}$ and the precipitate that formed was collected and dried in a vacuum at $80^{\circ} \mathrm{C}$ for $10 \mathrm{~h}$. The 
polyimide was obtained as a powder with a yield of 90\%: IR (film, $\mathrm{cm}^{-1}$ ) imide carbonyl at 1785,1727 , $\mathrm{C}=\mathrm{C}$ at 1605 , and aromatic $\mathrm{C}=\mathrm{C}$ at 1574,1513 ; UV $\lambda_{\max }=321 \mathrm{~nm}$ as the film and $\lambda_{\text {max }}=325 \mathrm{~nm}$ in the DMSO solution; ' ${ }^{1} \mathrm{H}$ NMR (DMSO- $d_{6}$, ppm) $\delta 7.86$, 7.81 ( s, $\mathrm{CH}=\mathrm{CH}$ ), 8.35-7.54 (br m, Ar). Polyimide $\eta_{\text {inh }}=0.33 \mathrm{dL} / \mathrm{g}$ in $0.5 \mathrm{~g} / \mathrm{dL}$ DMAc at $30^{\circ} \mathrm{C} ; T_{\mathrm{g}}=$ $267^{\circ} \mathrm{C}, T_{\text {dec }}=430^{\circ} \mathrm{C}$.

\subsection{Irradiation}

The polyimide dissolved in DMAc was spin-cast onto a cover glass followed by heating in vacuo at $50^{\circ} \mathrm{C}$ for $1 \mathrm{~h}$ and at $80^{\circ} \mathrm{C}$ for $2 \mathrm{~h}$. A $1 \mu \mathrm{m}$ thick film was then exposed to light with a high pressure 500 watt Xenon lamp. Intensity on the exposed surface was $1.5 \mathrm{~mW} / \mathrm{cm}^{2}$ in the range of $240-270 \mathrm{~nm}$, measured with an Ushio M-02 UV light meter. The exposed films were developed in 1,4-dioxane for 2 minutes and rinsed in ethanol for 1 minute. The photosensitivity $\left(D^{0.5}\right)$ and contrast $\left(\gamma^{0.5}\right)$ of the polyimide were obtained from the characteristic curve of the normalized film thickness versus exposure energy. Here $D^{0.5}$ is defined as the dose at
$50 \%$ film thickness loss, and

$$
\gamma^{0.5}=0.5 /\left[\log D^{1}-\log D^{0.5}\right] \text {. }
$$

The polyimide was also spin-cast onto silicon wafers and quartz plates for IR and UV spectra measurements, respectively. After irradiation, the conversion (photo-crosslinking rate or disappearance rate) of the carbon-carbon double bond was estimated by $\left|\left(A_{0}-A_{E}\right)\right| / A_{0}$, where $A_{0}$ and $A_{E}$ are the absorption intensity or transmittance of the polyimide in the UV or IR spectrum at an exposure dose of $d=0$ and $d=$ $E$, respectively.

\section{Results and Discussion}

\subsection{Synthesis and Characterization of Polyimide}

4,4'-Diaminochalcone (4DAC) was prepared from the condensation of an aldehyde with a ketone containing a protected amine group followed by hydrolysis catalyzed with acid as shown in Scheme

1. The structure of the synthesized $4 D A C$ was identified by elemental analysis and its spectrometric UV, IR and NMR characteristics presented in the Experimental Section.

The UV absorption of 4DAC appeared at the

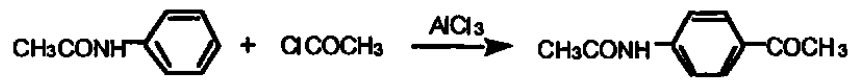

$4 a$ Yield: $82 \%, \mathrm{mp}: 169^{\circ} \mathrm{C}$
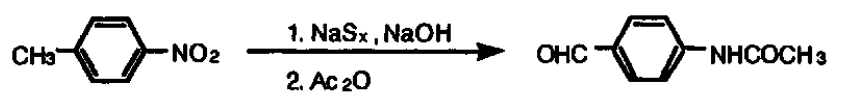

46 Vield: $47 \%$, mp: $155^{\circ} \mathrm{C}$

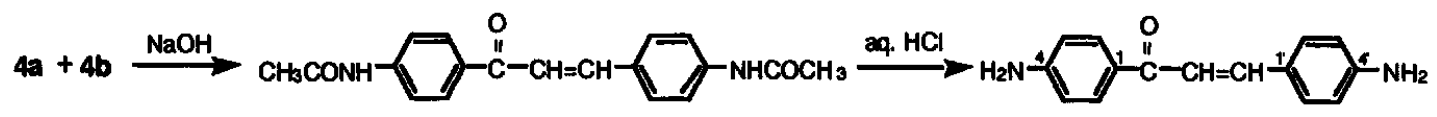

4c Yield: $95 \%$, mp: $269^{\circ} \mathrm{C}$ 4DAC Yield: $85 \%$, mp: $178^{\circ} \mathrm{C}$

Scheme 1

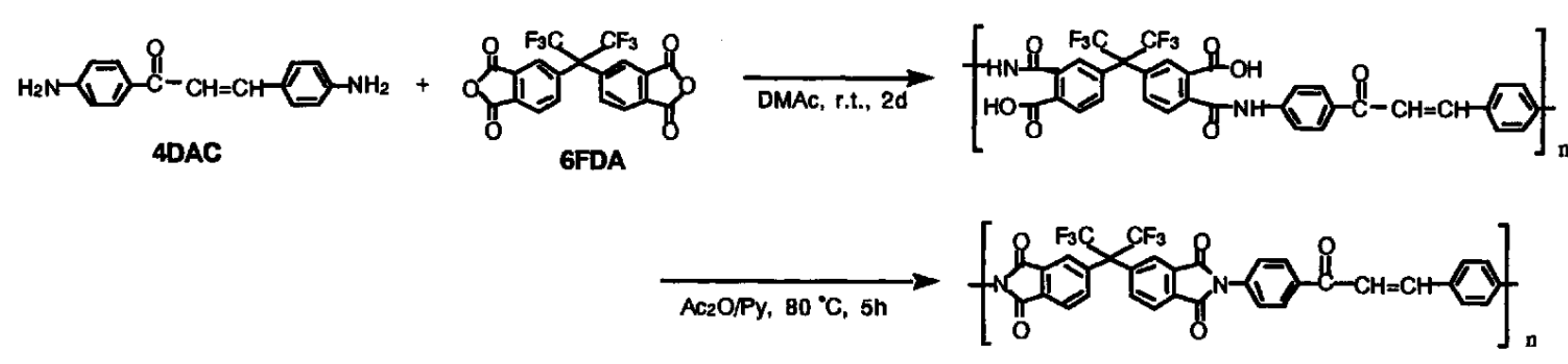

Scheme 2 
much longer wavelength of $397 \mathrm{~nm}$, which is attributed to the para substitution on the benzene ring of auxochromic groups such as the amino and $\alpha, \beta-$ unsaturated ketone. The para substitution of the benzene ring was also confirmed by its characteristic patterns of the overtone bands in the range of 2000$1650 \mathrm{~cm}^{-1}$ and the out-of-plane bending band at 820 $\mathrm{cm}^{-1}$ in the IR spectrum.

The thermogravimetric curve of 4DAC indicated that it is a monohydrate crystal, which is supported by the results from the elemental analysis and ${ }^{1} \mathrm{H}$ NMR. However, the influence of bound water on subsequent polymerization was not found.

The polycondensation of 4DAC and 6FDA was carried out in a homogeneous solution as shown in Scheme 2. The resultant poly(amic acid) was chemically converted into the polyimide by treating it with acetic anhydride and pyridine at $80^{\circ} \mathrm{C}$ in order to avoid the possible crosslinking of the double bond in the chalcone unit during the normal thermal curing. The complete chemical imidization was confirmed by IR spectroscopy.

The polyimide 4DAC-6FDA is readily soluble in strongly polar aprotic solvents such as DMAc, $N, N$-dimethyl formamide (DMF) and dimethyl sulfoxide (DMSO). Even in low polar solvents, e.g., 1,4-dioxane, tetrahydrofuran and chloroform, it still exhibited high solubility. This is explained by the decrease in the polymer-polymer chain interaction due to a bulky trifluoromethyl unit on the main chain.[6,9-10] As a comparison, 3,3',4,4'-benzophenonetetracarboxylic dianhydride (BTDA) or 4,4'oxydiphthalic anhydride (ODPA) failed as comonomers for preparing the polyimides with the
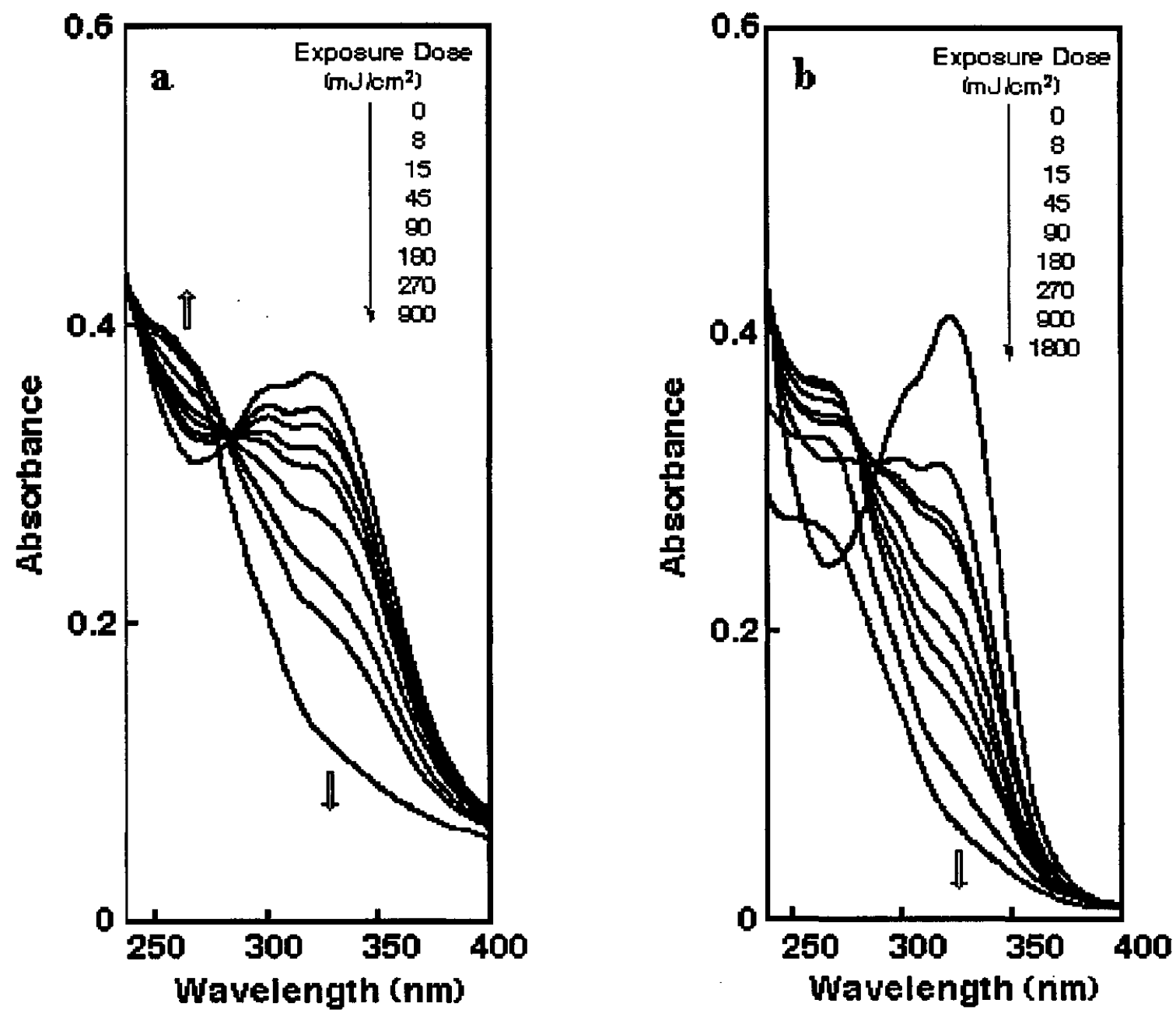

Figure 1 Changes in UV spectra of polyimide (a; film state, b; dioxane solution) 
chalcone moiety in our parallel studies, because these polymers usually precipitated from the solution during the chemical conversion of the poly(amic acid)s to polyimides.

The thermal behavior of the polyimide was determined by thermogravimetry (TG) and thermomechanical analysis (TMA). The polyimide had a $5 \%$ weight loss temperature $\left(T_{5}\right)$ at $485^{\circ} \mathrm{C}$, thus exhibiting an excellent thermal stability for use as polymeric photoresists. In addition, its glass transition temperature $\left(T_{\mathrm{g}}\right)$ was as high as $267^{\circ} \mathrm{C}$, indicating a high degree of backbone stiffness.

\subsection{Spectral Behavior upon Light Irradiation}

The effect of irradiation on the polyimide was investigated using a thin film and solution. Figure 1a illustrates the spectral changes in the UV absorption due to the photoreaction, where the absorption at $321 \mathrm{~nm}$ rapidly decreased with a small increase in the new band at the lower wavelength. This is regarded as the formation of cyclobutane rings through the $2+2$ cycloaddition of the carbon-carbon double bonds and the trans-cis isomerization of the chalcone unit, respectively.[15]

In the polyimide solution, the decrease in absorption at a lower wavelength was noted for an exposure dose of more than $900 \mathrm{~mJ} / \mathrm{cm}^{2}$ (see Figure 1b), which may be related to the clove of the formed cyclobutane ring by the prolonged irradiation and the decomposition of the carbon-carbon double bonds

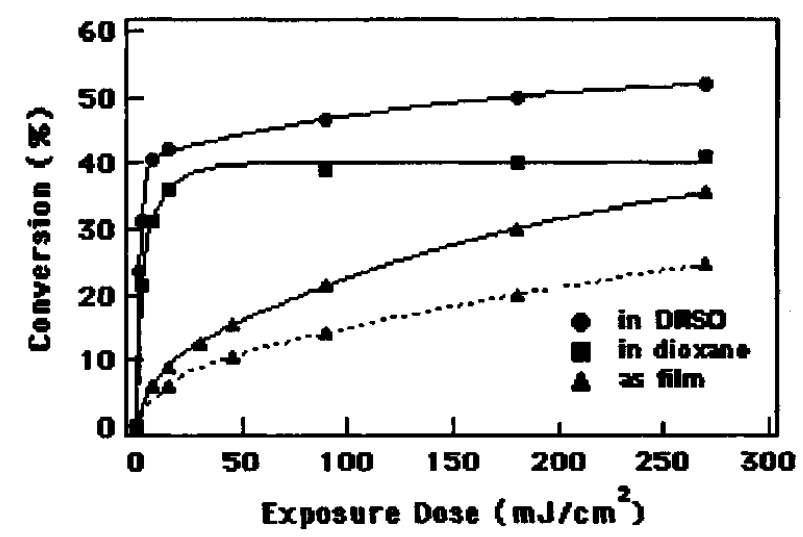

Figure 2 Photo-crosslinking rate of polyimide as a function of the exposure dose from UV (full line ) and IR (dotted line) spectra. without photo-crosslinking.[3]

The photo-crosslinking rate of polyimide in the film state was compared with that in dioxane and in DMSO solution in Figure 2. As shown, the photoreactivity in solution was greater than that of the film. Furthermore, the solvent polarity seems favorable to increase the photoreactivity.

The photo-crosslinking of the double bond was also observed in the IR spectrum of the polyimide film upon light irradiation (see Figure 3). The stretching absorptions of the $>\mathrm{C}=\mathrm{C}<$ bond at 1605 $\mathrm{cm}^{-1}$ gradually decreased with each exposure interval, showing the disappearance of the double bond due to the photo-crosslinking. The disappearance rate of $>\mathrm{C}=\mathrm{C}<$ with irradiation of the polyimide was also recorded in Figure 2.

\subsection{Photosensitivity}

Figure 4 gives the exposure characteristic curve for polyimide films cast on the cover glass, which presented a negative type of photoresist. From the characteristic curve, a photosensitivity $\left(D^{0.5}\right)$ of 130 $\mathrm{mJ} / \mathrm{cm}^{2}$ with a contrast $\left(\gamma^{0.5}\right)$ of 3.4 was obtained.

The scanning electron micrograph in Figure 5 is an example of a non-optimized negative image. The high resolution pattern was formed from a $3-\mu \mathrm{m}$ thick film of polyimide 4DAC-6FDA at a dose of $270 \mathrm{~mJ} /$

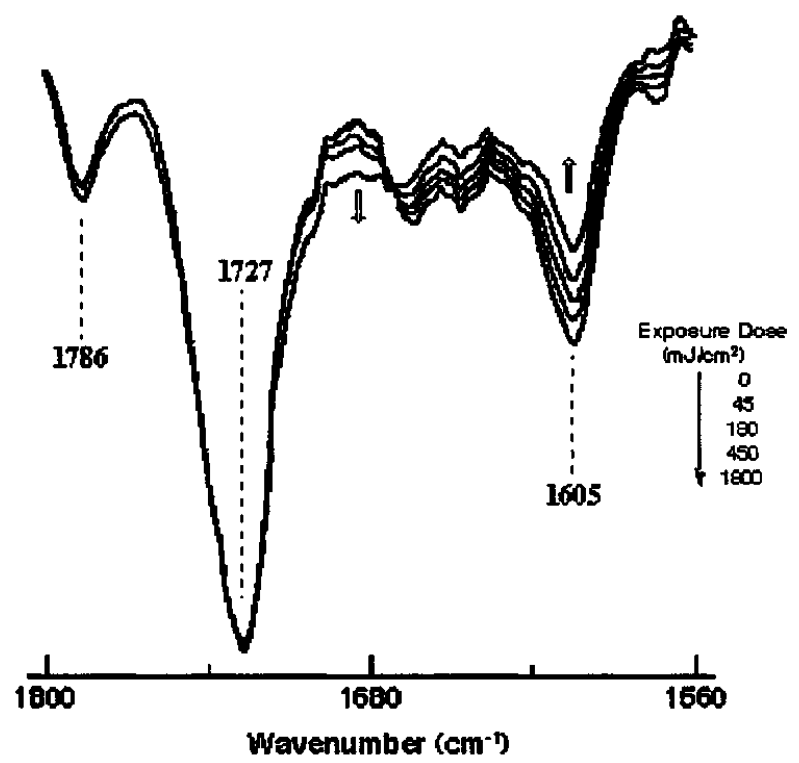

Figure 3 IR spectral behavior due to photoreaction of polyimide. 
$\mathrm{cm}^{2}$. It is understood from this result that the high photosensitivity and contrast of polyimide 4DAC6FDA contributed to its high resolution pattern.

\section{Conclusion}

A novel photoreactive polyimide with a chalcone moiety in the main chain was obtained by the polycondensation of 4DAC and 6FDA, which exhibited a negative working image with a photosensitivity of $130 \mathrm{~mJ} / \mathrm{cm}^{2}$ and a high contrast of 3.4 upon light irradiation. The polyimide possessed a good thermal stability $\left(T_{5}\right.$ at $\left.485^{\circ} \mathrm{C}\right)$ and was soluble even in low polar solvents such as 1,4-dioxane and chloroform.

\section{Acknowledgment}

The authors acknowledge Drs. M. Ohtsuka and K. Iizumi of the Tokyo Institute of Polytechnics for

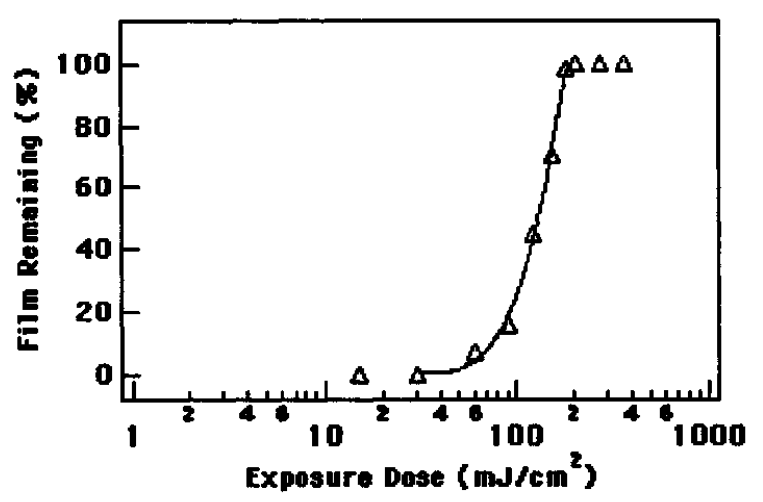

Figure 4 Exposure characteristic curve for polyimide

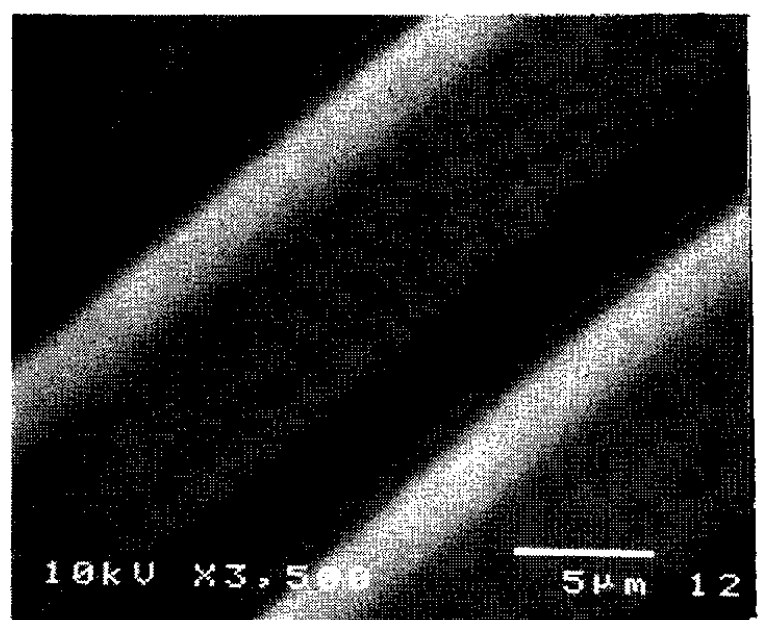

Figure 5 SEM image of polyimide $\left(270 \mathrm{~mJ} / \mathrm{cm}^{2}\right)$ their assistance in the determination of film thickness and SEM observations, and Messrs. K. Sueoka, J. Chiba, and M. Tsushima for their help in the monomer synthesis. This work was partly supported by a research grant from the Iwatani Naoji Foundation.

\section{References}

(1) R. Rubner, H. Ahne and E.Kunh, Photogr. Sci. Eng., 23 (1979) 303.

(2) Y. Yoda, T. Morikawa, T. Ando and A. Fukami, J. Macromol. Sci. Chem., A-21 (1984) 1641.

(3) S. Watanabe, S. Harashima and N. Tsukada, $J$. Polym. Sci., Polym. Chem. Ed., 24 (1986) 1227.

(4) A. Reiser, "Photoreactive Polymers", WileyInterscience, New York (1988).

(5) H. R. Allcock and C. G. Cameron, Macromolecules, 27 (1994) 3131.

(6) K. Feng, T. Matsumoto and T. Kurosaki, $J$. Photopolym. Sci. Technol., 9 (1996) 347.

(7) T. Matsumoto and T. Kurosaki, Macromolecules, 28 (1995) 5684.

(8) T. Matsumoto and T. Kurosaki, Reactive \& Functional Polymers, 30 (1996) 55.

(9) T. Omote, T. Yamaoka and K. Koseki, J. Appl. Polym. Sci., 38 (1989) 389.

(10) T. Omote, K. Koseki and T. Yamaoka, Macromolecules, 23 (1990) 4788.

(11) S. Saita and T. Nishikubo, Kobunshi Ronbunshu, 44 (1987) 737.

(12) A. V. R. Reddy, K. Subramanian, V. Krishnasamy and J. Ravichandran, Eur. Polym. J., 32 (1996) 919.

(13) J. L. Leiserson and A. Weissberger, "Organic Syntheses", E. C. Horning (ed.), John Wiley \& Sons, New York, Collective Vol. 3 (1965) p183.

(14) E. Campaigne, W. M. Budde and G. F. Schaefer, "Organic Syntheses", N. Rabjohn (ed.), John Wiley \& Sons, New York, Collective Vol. 4 (1967) p31.

(15) S. Watanabe, M. Kato and S. Kosakai, J. Polym. Sci., Polym. Chem. Ed., 22 (1984) 2801. 